\title{
La ilegalidad como orden. Hegemonía y política migratoria en la República Dominicana
}

\section{Lawlessness as order: Hegemony and immigration policy in the Dominican Republic}

\author{
Anselmo Muñiz* \\ Carlos Morel $^{* *}$
}

Instituto de Investigación Social para el Desarrollo, República Dominicana.

\author{
Cómo citar este artículo: Muñiz, A. y Morel, C. (2019). La ilegalidad como orden. Hegemonía y \\ política migratoria en la República Dominicana. Si Somos Americanos. Revista de \\ Estudios Transfronterizos, 19(2), 27-48. \\ DOI: $10.4067 / \mathrm{S} 0719-09482019000200027$
}

\section{Resumen}

Desde sus orígenes, la política migratoria dominicana frente a Haití ha estado marcada por una estrategia de doble cara: de un lado, se establece un orden cada vez más represivo y discriminatorio en perjuicio de los trabajadores migrantes haitianos y los dominicanos descendientes de estos trabajadores. Del otro, se generan excepciones extrainstitucionales a las reglas con el objetivo de generar una población desarraigada y desamparada, con un precario estatus político y legal en el país. Esta estrategia constituye un aspecto concreto de una hegemonía política que se sostiene sobre un relato conservador y racista acerca de la

* Máster en Métodos de Investigación Social y Estadística, Universidad de Manchester, Reino Unido. Instituto de Investigación Social para el Desarrollo (www.institutoisd.org), calle Estado de Israel, Plaza Centro del Este, módulo 105, Reparto del Este, Santiago, República Dominicana. Correo electrónico: a.muniz@institutoisd.org.

** Máster en Derecho y Desarrollo, Universidad de Manchester, Reino Unido Instituto de Investigación Social para el Desarrollo, calle Estado de Israel, Plaza Centro del Este, módulo 105, Reparto del Este, Santiago, República Dominicana. Correo electrónico: c.morel@institutoisd.org. 
ciudadanía y la identidad en la República Dominicana. Para enfrentar esta estrategia y redefinir la democracia dominicana en términos pluralistas, es necesario reconfigurar la ciudadanía como sujeto de la democracia. Entender la democracia, siguiendo a Balibar, como constitución de la ciudadanía, vale decir, de autoinclusión en una comunidad política de pares, permite ampliar el horizonte de las luchas de dominicanos desnacionalizados y de trabajadores migrantes en el país.

Palabras clave: migración, ilegalidad, relaciones dominico-haitianas.

\begin{abstract}
Since its inception, Dominican immigration policy with respect to Haiti has consisted in a Janus-faced strategy. On the one hand, an increasingly repressive and discriminatory legal order that is prejudiced against Haitian immigrants and their descendents has been established. On the other, extra-institutional exceptions are routinely generated in terms of regulations in order to create an uprooted and forsaken population with a precarious political and legal status. This strategy is a concrete aspect of a political hegemony built on a racist and conservative narrative about citizenship and identity in the Dominican Republic. In order to confront this strategy and redefine Dominican democracy in terms of pluralism, it is necessary to reconfigure the citizenry as the subject of democracy. If we define democracy as the constitution of citizenship following Balibar, or rather as inclusion in a political community of peers, we can expand the horizon of the political struggles of denationalized Dominicans and migrant workers in the country.
\end{abstract}

Keywords: Migration, lawlessness, Dominican-Haitian relations.

\title{
Introducción
}

La República Dominicana y la República de Haití comparten la isla de Santo Domingo (también conocida como La Española) en el mar Caribe. Los haitianos son el principal grupo de inmigrantes en la República Dominicana. La Encuesta Nacional de Inmigrantes de 2017, realizada por la Oficina Nacional de Estadísticas de la República Dominicana, estimó un total de 497.825 inmigrantes haitianos en el país, equivalente al $87 \%$ del total de los inmigrantes (Espinal, 2018). Este grupo ocupa un amplio segmento tanto del mercado de trabajo, como en el tejido sociocultural del país, pero, sin embargo, viven excluidos de la arena política. Asimismo, los descendientes de inmigrantes haitianos nacidos en territorio dominicano, por lo general viven en una situación muy marcada por el estigma de sus antepasados inmigrantes. 
La inmigración irregular de haitianos a la República Dominicana es interpretada comúnmente como el producto de un desorden institucional, ya sea por no poder impedir la entrada ilegal de inmigrantes haitianos (Balaguer, 1989; Castillo, 2012) o por no garantizar los derechos de esos migrantes y sus descendientes (Bosch, Pérez y Rodríguez, 2018; Fletcher y Miller, 2004; Lozano, 2011; Martínez, 2014; Petroziello, 2012).

Este artículo pretende demostrar que la política migratoria de la República Dominicana frente a la inmigración haitiana se caracteriza por una normativa restrictiva y confusa. Al mismo tiempo, el Estado ha sido históricamente uno de los principales promotores del reclutamiento de mano de obra haitiana para sectores clave de la economía del país, muchas veces en contra de su propia regulación. Se plantea que la aparente incoherencia de la política migratoria dominicana esconde la estructuración de un orden institucional diseñado sobre la base de la ilegalidad. Además, apoyándose en la teoría de la hegemonía de Gramsci y el análisis de la ciudadanía de Balibar, el artículo propone reenfocar la lucha de las organizaciones de la sociedad civil que defienden los derechos de inmigrantes haitianos y sus descendientes en la República Dominicana como una lucha política por la constitución de la ciudadanía dominicana.

Para esto, en la primera sección se hace un breve recuento de la inmigración haitiana a la República Dominicana, su vínculo con ciertos sectores de la economía de este país y se pone especial énfasis en la evolución de la legislación migratoria. Asimismo, se explica la situación política y jurídica actual que ha devenido en un conflicto sobre la nacionalidad dominicana para los descendientes de inmigrantes haitianos. En la segunda sección, se exponen los principales relatos sobre la inmigración haitiana a la República Dominicana en la literatura especializada. En esta sección se argumenta que si bien es posible identificar dos grandes relatos, el del conflicto y el institucionalista, ambos comparten la premisa de que el origen del conflicto es la debilidad institucional del Estado dominicano. En la tercera sección, se analizan las continuidades en la política migratoria dominicana desde principios del siglo pasado para argumentar que esta se enmarca en una estrategia hegemónica desplegada desde el Estado por la élite gobernante con el objetivo de fortalecer un orden político racista y excluyente que se sustenta, en buena parte, en el subsidio que significa la explotación de poblaciones vulnerabilizadas. En la cuarta sección, se examinan los límites del discurso institucionalista en la defensa de los derechos humanos, y se argumenta que solo es posible avanzar si se plantea esta lucha en términos abiertamente políticos. En particular, es necesario cuestionar el vínculo de los actores que en un momento dado ocupan el gobierno con el orden hegemónico y enfrentarlos desde la política buscando construir una nueva hegemonía que descanse en valores democráticos. 


\section{La inmigración haitiana a la República Dominicana en contexto}

La inmigración haitiana a la República Dominicana está íntimamente vinculada a la industria azucarera. Si bien el desarrollo de la industria azucarera se inicia a principios de la década de 1870, en sus orígenes, la mano de obra era principalmente de otras islas del Caribe (Del Castillo, 2005). Bajo la intervención militar de los Estados Unidos de América a la República Dominicana entre 1916 y 1924, se inició un proceso de modernización y desarrollo de la industria del azúcar, impulsado principalmente por el empleo de trabajadores migrantes haitianos como principal fuerza de trabajo, quienes reemplazaron a los trabajadores migrantes de origen cocolo (Del Castillo, 2005; Fletcher y Miller, 2004; Martínez, 1999).

Esto ocurría en el contexto de un marco regulatorio racista, creado por la primera ley de inmigración dominicana, promulgada en 1912, cuyo contenido era similar al de una orden administrativa promulgada en 1905. Esta norma declaró que los braceros (obreros de las plantaciones de caña de azúcar) no blancos, así como los inmigrantes de las colonias europeas de América, de África, de Asia y de Oceanía, requerían de un permiso especial dictado por el Poder Ejecutivo. Mientras que los blancos, de Europa o de los países independientes de las Américas, no requerían de este permiso (Capdevila, 2004).

En 1919, el gobierno militar de Estados Unidos emitió la orden ejecutiva $\mathrm{N}^{\circ} 372$, que endureció la regulación de la entrada de trabajadores inmigrantes no blancos al exigir un permiso emanado de la Secretaría de Estado de Agricultura e Inmigración, e indicaba puntos específicos de entrada al país para estos (Capdevila, 2004). Esta orden ejecutiva convertía en delito el estar en el país sin dicho permiso, que se castigaba con una multa y prisión antes de ser deportado (Capdevila, 2004).

Durante la dictadura de Rafael Leónidas Trujillo (1930-1961), el empleo de trabajadores migrantes haitianos para la industria azucarera se amplió y el Estado tomó el control de la contratación de estos trabajadores (Martínez, 1999, 2003). Esta política de empleo masivo de trabajadores migrantes haitianos fue acompañada por el endurecimiento de la regulación de inmigración y la creación de mecanismos excepcionales a la discrecionalidad del Poder Ejecutivo. Capdevila (2004) señala que estas prácticas ya venían dándose desde el gobierno militar norteamericano.

En 1932, la dictadura promulgó la Ley $\mathrm{N}^{\circ} 279$, que estableció unos impuestos para los inmigrantes no blancos, pero también se promulgó la Ley $\mathrm{N}^{\circ} 331$, que exoneraba de esos impuestos a los obreros agrícolas e industriales, siempre que estos tuvieran un contrato de trabajo (Capdevila, 2004). El año siguiente, 1933, se dictó la Ley $\mathrm{N}^{\circ} 597$ para la “dominicanización del trabajo", regulación que limitó el número de extranjeros que podían ser contratados por un empleador: solo un $30 \%$ de la plantilla total de cualquier empleador determinado (Capdevila, 2004). Sin embargo, en su artículo 2 dicha ley permitía al Poder Ejecutivo emitir permisos especiales para las empresas agrícolas, de modo que pudieran 
contratar braceros extranjeros en exceso de la cuota establecida. Esto sentó las bases de un sistema de corrupción sin precedentes que permaneció intacto por décadas (Capdevila, 2004).

Las anteriores disposiciones fueron repetidas por sucesivas leyes, incluidos los códigos de Trabajo de 1951 y 1992 (Capdevila, 2004). Este nivel de discrecionalidad otorgado al Poder Ejecutivo es típico de la regulación migratoria. Por un lado, la ley es restrictiva y, por otro, se otorga al gobierno la posibilidad de establecer excepciones temporales al cumplimiento de la ley.

Además, durante la década de 1930 las comunidades dominicanas ubicadas en la frontera con Haití fueron militarizadas y sujetas a un proceso de "blanqueado" mediante la introducción de inmigrantes no-negros (Dilla, 2004b), política que llevaría en el año 1937 a la matanza de miles de haitianos en la frontera dominico-haitiana (hecho comúnmente denominado la masacre del perejil). Sin embargo, este hecho no tuvo mayor impacto en los haitianos inmigrantes que vivían en los bateyes ${ }^{1}$ de la región sureste del país, donde se concentraban los ingenios de azúcar (Dilla, 2004b; Martínez, 1999).

En 1939, los gobiernos dominicano y haitiano firmaron un tratado denominado Modus Operandi, cuyo objetivo era establecer un sistema para que las autoridades dominicanas pudieran repatriar inmigrantes haitianos (Ley $\mathrm{N}^{\circ} 199,1939$ ). Es importante notar que este tratado fue un seguimiento al Acuerdo de Washington de 1938, firmado por el gobierno dominicano y el haitiano como consecuencia de la indicada masacre de 1937. Mientras que el propósito declarado tanto en el Acuerdo de Washington de 1938, como en el firmado un año después, en 1939, era evitar la repetición de la matanza de 1937, el efecto real fue crear la base jurídica de un sistema de expulsiones en masa y al azar que permanece hasta hoy día (Capdevila, 2004).

También en 1939, el gobierno dominicano promulgó una nueva ley de inmigración (Ley $\mathrm{N}^{\circ}$ 95, 1939) que unificaba y sistematizaba todas las medidas anteriores. Esta nueva ley clasificó a los extranjeros en suelo dominicano como migrantes y no migrantes en función del tipo de permiso que utilizaban para la entrada al país. Además, esta ley creó un órgano administrativo especial para manejar el "ingreso, la residencia y la expulsión de los extranjeros" (Ley $\mathrm{N}^{\circ}$ 95, 1939).

La misma ley establecía que los trabajadores temporales solamente serían admitidos en territorio dominicano bajo una petición del sector agroindustrial donde iban a trabajar, y fijaba las condiciones y las cuotas permitidas por las autoridades competentes (Ley $\mathrm{N}^{\circ} 95$, 1939). Por otra parte, esta ley estableció un nuevo sistema de impuestos para los diferentes permisos y permitió a las empresas agrícolas recoger los impuestos directamente de sus

1 Los bateyes (singular, batey) son los caseríos formados por las viviendas de los trabajadores de los ingenios azucareros. Con el tiempo se conformaron pequeños pueblos en los que hoy día habitan descendientes de trabajadores migrantes de la industria azucarera. 
empleados, para luego pagarlos al Estado. Bajo esta regulación, ser trabajador extranjero sin los documentos y permisos apropiados continuó siendo delito, el cual se castigaba con pena de prisión, multa y posterior deportación (Ley $\mathrm{N}^{\circ}$ 95, 1939).

En efecto, esto creó un sistema de semiesclavitud en la agroindustria, en su mayoría fincas de caña de azúcar. Los terratenientes pagaban los gastos legales para traer trabajadores haitianos y emplearlos durante algún tiempo antes de enviarlos de regreso a su país cuando ello les fuera conveniente, colocando a estos trabajadores en una situación de dependencia material y jurídica, debilitando también su posición de negociación (Capdevila, 2004).

También durante la dictadura de Trujillo (1930-1961) era una práctica común del gobierno dominicano recoger violentamente a los inmigrantes haitianos para obligarlos a trabajar en las plantaciones de azúcar, sobre todo en las que eran propiedad del dictador (Martínez, 1999), dada la continua necesidad de mano de obra barata para la industria azucarera. En 1952, los gobiernos dominicano y haitiano firmaron el primero de muchos tratados para la contratación de trabajadores migrantes haitianos (Resolución $\mathrm{N}^{\circ} 3200,1952$ ). Esto se convirtió en una práctica común hasta 1986, cuando cayó la dictadura de Jean-Claude Duvalier en Haití (Fletcher y Miller, 2004). Estas prácticas han sido definidas como formas de esclavitud contemporánea (Antonin, 1982).

Con el paso del tiempo, los trabajadores haitianos comenzaron a ser empleados en muchas otras áreas de la economía dominicana, sobre todo en la construcción, así como en otros sectores de la agricultura, como el arroz y el café (Fletcher y Miller, 2004). De acuerdo con Lozano (1998), el empleo de trabajadores migrantes haitianos en otros sectores de la agricultura, como el café y el arroz, se hizo intensivo en la década de 1980. Para 1985, el 54\% de los jornaleros en esos sectores eran migrantes haitianos (Lozano, 1998).

En el caso de los sectores de la construcción y el banano, el empleo intensivo de trabajadores es más reciente. Según un informe de 2011, encargado por el Ministerio de Trabajo de la República Dominicana, entre 2000 y 2010 la proporción de trabajadores de la construcción que eran inmigrantes haitianos pasó de 27\% a 53\% (Ministerio de TrabajoObservatorio del Mercado Laboral Dominicano, 2011). Mientras que en el sector bananero el empleo intensivo de inmigrantes haitianos se inició en la década de 2000, para el 2010 alcanzó un promedio de 66,3\% de los trabajadores de ese sector (Ministerio de TrabajoObservatorio del Mercado Laboral Dominicano, 2011).

Tanto Dilla (2004b) como Fletcher y Miller (2004) señalan que este flujo migratorio ha estado marcado por una lucrativa industria de tráfico humano en la frontera dominicohaitiana, en el que participan funcionarios de los gobiernos de ambos países, incluidos miembros de las fuerzas armadas. 
Asimismo, este flujo migratorio ha sido muy importante para la economía dominicana. Estudios recientes estiman entre 5,4\% y 7,4\% el aporte de los inmigrantes haitianos al valor agregado anual de la economía dominicana (Ciriaco y Vargas, 2018; Lizardo y Grateraux, 2013). En contraste, los trabajadores haitianos devengan un ingreso promedio de 2,3 veces menor al de inmigrantes de otras nacionalidades (Cáceres, Lozano, Durán, Montero y Otáñez, 2018). Además, son objeto de violaciones sistemáticas a los derechos laborales y de seguridad social: por ejemplo, retención de pagos, horas de trabajo excesivas, falta de pagos de horas extras, ausencia de vacaciones y otras prestaciones (Bosch, Pérez y Rodríguez, 2018; Martínez, 2014; Ministerio de Trabajo-Observatorio del Mercado Laboral Dominicano, 2011; Petroziello, 2012). Los descendientes de migrantes haitianos también se encuentran en situaciones similares (Espinal, 2018).

Es importante señalar que el efecto de la evolución normativa expuesta más arriba, con sus peculiares excepciones, generó una población de inmigrantes que entraron con permisos temporales, los que una vez perimidos, dejaban a estos inmigrantes con un estatus legal precario y bajo amenaza de deportación. Debido a esta amenaza y su situación migratoria irregular, los inmigrantes son menos propensos a organizarse para luchar por mejores salarios y condiciones de trabajo. En otras palabras, como ejército de reserva industrial, el influjo de trabajadores migrantes haitianos permite a la élite dominante dominicana deprimir los salarios de la generalidad de los trabajadores.

Lo anterior pone de manifiesto el comportamiento aparentemente contradictorio del Estado dominicano con respecto al asunto migratorio. Por un lado, cada reforma migratoria tendió a ser más restrictiva y discriminatoria contra los inmigrantes haitianos, mientras por el otro, el propio Estado dominicano (y sus agentes en el caso del tráfico de personas en la frontera) promovió activamente el reclutamiento de trabajadores haitianos para distintas áreas de la economía dominicana.

Después de un siglo, esta política implícita ha derivado en un conflicto político en torno al estatus de ciudadanía de los descendientes nacidos en suelo dominicano de trabajadores haitianos. Antes de 2007 estaba claro que en el Estado dominicano los niños nacidos en territorio dominicano de inmigrantes indocumentados eran ciudadanos dominicanos. Pero en 2007, la Junta Central Electoral (órgano encargado del Registro Civil) en aplicación de la Ley General de Migración promulgada en 2004, emitió la circular 017 y la Resolución 12-2007 e inició un proceso arbitrario de suspender las actas de nacimiento de dominicanos descendientes de inmigrantes haitianos, bajo la excusa de que eran documentos obtenidos fraudulentamente. Este hecho estimuló una serie de batallas legales entre las organizaciones de derechos humanos y el Estado dominicano, que incluye varios casos en el sistema interamericano de protección de los derechos humanos (ver por ejemplo, Caso de personas dominicanas y haitianas expulsadas vs. República Dominicana; Caso Nadege Dorzema y otros vs. República Dominicana; Caso de las niñas Yean y Bosico vs. República Dominicana). 
Un hito importante en este contexto fue la Sentencia 168/2013 de octubre de 2013 del Tribunal Constitucional Dominicano, ${ }^{2}$ que ordenó negar la nacionalidad dominicana a los descendientes de inmigrantes haitianos que no pudieran demostrar la regularidad del estatus migratorio de sus padres. Ante la reacción adversa de la comunidad internacional y de las organizaciones defensoras de derechos humanos locales, el Estado dominicano se vio obligado a promulgar la Ley 169-14 para permitir la regularización o naturalización de las personas afectadas por la sentencia del Tribunal Constitucional.

Esta ley hizo la distinción entre las personas que ya gozaban de la nacionalidad dominicana antes de la sentencia -a quienes abrió la vía de la naturalización- y aquellas que no gozaban de la nacionalidad, por lo que se les consideró inmigrantes sin importar su lugar de nacimiento. Para estos últimos, junto con los demás inmigrantes indocumentados, la ley ordenó un Plan Nacional de Regularización de Extranjeros, con el objetivo de permitir la regularización de su estatus como migrantes, para luego optar por una vía exprés de naturalización.

La aplicación de la ley ha estado plagada de dificultades y trabas. El primer grupo de personas, denominado grupo "A" en la aplicación de la ley, fue expuesto a violaciones del debido proceso, pues se les solicitó a estas personas documentos no establecidos previamente en la ley, junto con someterles a entrevistas de "inspección" sin un abogado presente, haciendo más confuso aun un proceso que de por sí no estaba claro (Centro Bonó, 2015). Al segundo grupo, denominado grupo "B”, quienes debían acogerse al Plan Nacional de Regularización de Extranjeros, se le sometió a un proceso de doble exclusión. Por un lado, territorial, ya que no todas las oficinas de la Junta Central Electoral estaban preparadas para realizar el proceso, por lo que muchas personas tuvieron que viajar a la capital para acogerse a la ley (Centro Bonó, 2015). Por otro lado, fueron excluidos aquellos nacidos después de 2007, a pesar de que constitucionalmente no fue hasta el 2010 cuando se eliminó la posibilidad de que hijos de extranjeros irregulares obtuvieran la nacionalidad (Centro Bonó, 2015).

De acuerdo con los datos de la Encuesta Nacional de Inmigrantes de 2017, la situación luego de la Ley 169-14 y su plan de regularización es la siguiente: de la población inmigrante haitiana, solo el 41,4\% (un estimado de 203.448 personas) participó en el plan de regularización, el restante 58,5\% no participó (Espinal, 2018). De aquellos que sí participaron, a la gran mayoría (el 73\% equivalente a 141.329 personas) se les entregó un carné temporal que no constituía una visa, residencia, ni permiso de trabajo, mientras que a

2 A raíz de un recurso de alzada contra una sentencia en materia de amparo, en la cual la accionante buscaba que se le retornara su documento de identidad, retenido por la Junta Central Electoral, el Tribunal Constitucional no solo validó la acción de la Junta de retener el documento de identidad de la accionante, sino que le ordenó al cuerpo administrativo que iniciara la investigación de los registros de nacimiento de todas las personas nacidas en territorio dominicano, a partir de 1929, cuyos padres podrían haber sido inmigrantes indocumentados, con el objetivo de retirarles la nacionalidad dominicana si se detectaba algún fraude.

34 Si Somos Americanos. Revista de Estudios Transfronterizos 
los demás se les otorgaron otro tipo de constancia (Espinal, 2018). De hecho, según datos de la Dirección General de Migración de la República Dominicana, al 86\% de las personas que se acogieron al plan, se les asignó el estatus de "no residente" (Dirección General de Migración, 2017). Cabe destacar que el carné temporal de no residente no tiene validez para ningún tipo de trámite legal dentro o fuera de la República Dominicana y solo sirve para evitar la deportación a Haití (Belique, 2017).

En relación con la población descendiente de inmigrantes haitianos, la Encuesta Nacional de Inmigrantes 2017 encontró que cuando ambos progenitores son haitianos, solo el $57,2 \%$ de los descendientes tienen acta de nacimiento dominicana, mientras que cuando uno de los progenitores es dominicano y el otro haitiano, el 65,6\% de los descendientes posee acta de nacimiento dominicana (Espinal, 2018). En el caso de los descendientes de inmigrantes de otras nacionalidades, estas proporciones son de 96,4\% y $93,2 \%$, respectivamente (Espinal, 2018). Se estima que hay 46.235 personas menores de edad sin ningún tipo de documentación, casi en su totalidad descendientes de inmigrantes haitianos (Espinal, 2018).

Por otro lado, respecto de las personas con nacionalidad dominicana que fueron desnacionalizadas por la sentencia 168/2013, los datos de la referida encuesta permiten verificar que, de 6.594 personas en esta situación, el 88,6\% se acogió a la Ley 169-14, pero menos de la mitad de estos (48,5\%) logró obtener sus documentos (Espinal, 2018).

Asimismo, los descendientes de los inmigrantes haitianos enfrentan mayores niveles de exclusión que los descendientes inmigrantes de otras nacionalidades. Los descendientes de inmigrantes haitianos reciben ingresos promedios de alrededor de un $70 \%$ menor que los descendientes de inmigrantes de otras nacionalidades (Espinal, 2018). Además, mientras solo el 8,8\% de los hijos de ambos progenitores haitianos y el 25\% de los hijos de un progenitor haitiano y uno dominicano tiene seguro médico, estos porcentajes aumentan a más del $70 \%$ entre los hijos de uno o ambos padres de otras nacionalidades (Espinal, 2018).

Lo cierto es que la Ley 169-14 sigue el mismo patrón que las anteriores regulaciones de migración. Primero, genera un estándar normativo restrictivo de difícil cumplimiento para los inmigrantes haitianos, o para sus descendientes nacidos en territorio dominicano, y además, su cumplimiento es difuso. De esta manera, lejos de resolverse el limbo legal de los inmigrantes haitianos y los dominicanos de ascendencia haitiana, se agrega una nueva regla que una gran parte de esa población incumple bajo la tolerancia del Estado, pero que en cualquier momento puede ser causa de la expulsión de estas personas fuera del territorio dominicano. En este sentido, la referida ley ha sentado las bases para un nuevo sistema de segregación, al mismo tiempo que ha logrado silenciar a la opinión pública preocupada de los derechos de los inmigrantes y de los descendientes de inmigrantes (Belique, 2017). 


\section{Panorama de la literatura académica sobre la inmigración haitiana a la República Dominicana}

La inmigración haitiana a la República Dominicana y, de manera más amplia, las relaciones entre ambos países, han sido considerablemente estudiadas, debido principalmente al contraste socioeconómico entre los dos países y la precaria situación migratoria de los trabajadores migrantes haitianos. De forma general, los trabajos académicos abordan el tema desde dos discursos. Por un lado, el discurso del "conflicto" y, por el otro, un discurso institucionalista.

El discurso del conflicto analiza las relaciones binacionales desde una perspectiva histórica, resaltando los eventos violentos de la isla y las diferencias culturales acumuladas desde tiempos coloniales. Como explica Mayes (2015), esta visión fue aceptada por la élite dominicana desde la década de 1920, cuando se desarrolló un pensamiento hispanista que buscaba esconder las raíces africanas de la República Dominicana y pretendía definir al país como un "no-Haití". El sustrato de esta posición es que entre las naciones subyace un conflicto no resuelto que produce una serie de tensiones entre ambos países, pero también entre haitianos y dominicanos al interior de República Dominicana. Esta visión alimenta un imaginario acerca de la raza, la cultura, la religión y la nación en el que dominicanos y haitianos se presentan como adversarios o hasta enemigos.

Este discurso alcanzó un estatus hegemónico en la política dominicana durante la dictadura de Trujillo, resultado de las obras de intelectuales del régimen como Peña Battle, Balaguer y Francisco J. Peynado (Mateo, 2004). En las últimas dos décadas ha tenido un repunte en un contexto de una renovada política neonacionalista, con importantes paralelismos con las llamadas derechas alternativas de Estados Unidos y de Europa (Castillo, 2012). En este contexto, se resalta el empleo de recursos retóricos que presentan a Haití como un Estado opresor y a los inmigrantes haitianos como invasores que ponen en riesgo la independencia dominicana y la existencia misma de la dominicanidad.

En oposición al discurso del conflicto, ha surgido una línea de pensamiento que explica la historia cultural, racial y económica de ambos países como una relación compleja que ha sido experimentada de forma diferente por los distintos estratos de las poblaciones de ambos países. Por ejemplo, Howard (2001) hace un esfuerzo por complejizar la racialización en la República Dominicana y por explorar cómo afecta a diferentes grupos sociales en el país. Asimismo, Ricourt (2016) y Eller (2016) exploran cómo el discurso del conflicto fracasa en explicar el sincretismo y la colaboración que se dan en diferentes ámbitos de la sociedad dominicana y su relación con Haití, especialmente en la frontera. En este ámbito, utilizando ejemplos de la diáspora dominicana y haitiana, García-Peña (2016) analiza el impacto del imperialismo estadounidense en la conformación de las fronteras raciales entre dominicanos y haitianos, argumentando que, al validar una visión específica sobre el cuerpo, el lenguaje y la cultura, se crea un archivo de fronteras nacionales y 
raciales. Más aún, afirma la autora, este archivo de fronteras genera, por exclusión, un archivo alternativo de identidades (el otro excluido) que funciona como referente para enfrentar la perspectiva racista, que es dominante en la dominicanidad tal y como se entiende en la isla.

Este discurso se enfoca primordialmente en las dinámicas que se desarrollan en torno a la migración haitiana en la República Dominicana. Augelli (1980) describe una situación de una frontera legalmente no terminada y da cuenta de los esfuerzos del gobierno dominicano, que comprenden acciones violentas y violatorias de derechos humanos, como un intento de reafirmar la frontera y de establecer legalidad. Otros como Ferguson (2003) y Kristensen y Wooding (2013) hacen referencia directa al problema de los derechos del inmigrante, ubicando su discurso desde una posición "institucionalista", que considera el Estado dominicano como institucionalmente débil, provisto de un marco legal incapaz de lidiar correctamente con la población migrante. Más recientemente, y como consecuencia del fallo 168-13 del Tribunal Constitucional de la República Dominicana, la discusión ha versado sobre la estructura racista y xenófoba que predomina en este país, y el fracaso del gobierno de turno por mejorar la situación (Mayes, 2017).

Ambos discursos, sin embargo, coinciden en la aparente debilidad institucional del Estado dominicano para imponer un orden legal, ya sea frente a la migración descontrolada (discurso del conflicto) o frente a intereses conservadores y corruptos (discurso institucionalista). Al respecto, algunos autores se han planteado examinar el problema desde una perspectiva distinta a partir de cómo la inmigración haitiana y las relaciones entre ambos países han contribuido al desarrollo de los actuales regímenes económicos y políticos de ambos Estados.

En este sentido, Lozano (1998) examina la importancia histórica del trabajo de los braceros haitianos para el desarrollo capitalista dominicano, en un contexto en el que el Estado dominicano ha sido incapaz de hacer respetar los derechos humanos de estos trabajadores migrantes, sometidos así a un esquema de explotación injusto, que impide su integración plena en la sociedad dominicana. Asimismo, Dilla (2004a) expone cómo la combinación del marco nacionalista de la cultura política de ambos países, con el vacío de políticas públicas, limita la posibilidad de un cambio en las percepciones mutuas de dominicanos y haitianos en la frontera, a pesar de las múltiples experiencias de solidaridad que surgen de la necesidad. Más aún, este autor examina cómo esta situación aumenta la vulnerabilidad de los migrantes haitianos en la República Dominicana, cuya explotación en condiciones abusivas es lucrativa para ciertos sectores de la economía dominicana. Por su parte, Théodat (1998) recupera la crítica al colonialismo para rastrear cómo las fronteras del imperialismo europeo se transforman en "barreras" entre los pueblos haitiano y dominicano, provocando una "insularidad dividida" en la que ambas naciones actúan como si estuvieran en islas separadas. Sin embargo, continúa Théodat (1998), el desarrollo del intercambio comercial y una emigración multiforme que coincide en destinos (Nueva York 
es la segunda ciudad con más dominicanos o haitianos), abre el potencial para una reconfiguración de dos pueblos que comparten "el camino del mar".

Esta perspectiva -sobre la funcionalidad de la explotación de la mano de obra haitiana en el orden político y económico dominicano- puede ser profundizada aún más si se considera en su contexto como cuestión central del desarrollo de una estrategia de las élites dominicanas, donde a partir de un aparente desorden institucional se desarrolla un orden hegemónico particular.

\section{Hegemonía: el orden en el "desorden"}

Existen situaciones en las que la violación sistemática del orden institucional puede ser parte integral de ese mismo orden. Para aclarar esta afirmación conviene diferenciar entre dos tipos de violación sistemática del orden institucional. La primera, es la violación por parte de una entidad paraestatal que compite con el Estado por el control de espacios sociales significativos. Este es el caso primordialmente del crimen organizado, aunque también se pueden incluir grupos en rebeldía al Estado (violenta o no violenta) como lo era la guerrilla en Colombia previo al acuerdo de paz. En estas situaciones, agentes u organizaciones particulares con gran poder retan la institucionalidad del Estado y con ello a la élite gobernante. El Estado deberá imponer su autoridad o arriesgar una crisis de legitimidad que obligue a refundar el régimen político (incluso por parte de los mismos agentes que generaron la crisis en primer lugar, como en el caso de una revolución exitosa).

Por otro lado, la violación sistemática de las instituciones del Estado puede cometerse por parte de agentes que operan desde y con el apoyo de los principales centros de poder político. Es decir, agentes que no compiten con el Estado, sino que cooperan con él. Así, se trata de situaciones en la que el orden institucional supone la existencia de reglas más allá de las leyes. En este tipo de situaciones se generan espacios en los que las instituciones formales funcionan selectivamente, siguiendo criterios definidos fuera de la formalidad estatal, como es el caso de la política migratoria dominicana desde sus orígenes.

En este segundo caso no se trata de "restablecer el orden", porque la excepcionalidad y la violación de la ley es, de hecho, parte del mismo orden político. Para comprender mejor esta situación, es preciso analizarla desde la perspectiva de la teoría de la hegemonía basada en Gramsci.

La hegemonía es la unidad política, intelectual y moral dentro de un orden social, que surge cuando una clase social o grupo dominante es capaz de proyectar sus valores, intereses e ideas como las del conjunto de la sociedad (Gramsci, 2011). En consecuencia, la ideología de la clase hegemónica se presenta como el sentido común de la sociedad (Gramsci, 2011). Lo anterior conlleva a que de una manera u otra los objetivos, intereses 
e ideas de una clase o grupo en particular, necesitan operar como una universalidad que trasciende tales clases o grupos y sean asumidos por una parte considerable de la sociedad completa (Laclau, 2000).

Asimismo, la hegemonía no se desliga de la violencia, o por lo menos de la promesa de esta, como garantía del sometimiento a las reglas y al mantenimiento de la hegemonía actual (Thomas, 2010). Una hegemonía política concreta involucra una compleja relación entre la capacidad de coerción del Estado y el consentimiento de amplios segmentos de la sociedad al dominio de un grupo concreto (Thomas, 2010). Las instituciones formales e informales de la sociedad trabajan para fortalecer ese consentimiento, siempre bajo la sombra de la posibilidad de violencia contra quienes se aparten de las normas establecidas. Es en este contexto que funcionan las normas migratorias dominicanas.

El desarrollo de la política migratoria dominicana es el resultado de un proyecto hegemónico particular. El racismo y la xenofobia son dispositivos de esa hegemonía para facilitar y justificar la explotación y exclusión de los inmigrantes haitianos con el objetivo de extraer valor de su trabajo, subsidiando un modelo económico ineficiente para así mantener altas tasas de ganancia para la cúpula económica y política que maneja ese modelo.

En este sentido, Capdevila (2004) argumenta que, en sus primeras etapas, el objetivo de la regulación migratoria dominicana no era impedir o restringir la inmigración haitiana, sino más bien someterla a las necesidades específicas de la industria de la caña de azúcar. Esta industria requiere una mano de obra abundante, barata y obediente; tal cosa no iba a ser posible con el campesinado "belicoso" y en gran parte independiente de la República Dominicana. Así que la respuesta era obvia: el establecimiento de una población de "desarraigados", excluidos de los procedimientos formales del gobierno dominicano, sin derechos y sujetos a la violencia del Estado, de las élites económicas y de prácticamente cualquier otra persona. Tal población sería lo suficientemente vulnerable para ser disciplinada y convertida en una fuerza de trabajo dócil y barata.

El aspecto clave de esta estrategia es que la regulación tiene que ser lo suficientemente severa como para infundir miedo en la población migrante y dotar al Estado de una estrategia de salida para mantener dicha población bajo control. Pero al mismo tiempo, la legislación no se puede cumplir por completo o de lo contrario sería contraproducente (creando una escasez de mano de obra, en lugar de sobreabundancia). Por lo tanto, el orden deseado es un desorden legal, donde se requiere la violación activa de la ley y la creación de innumerables lagunas que pueden ser controladas por las élites y el Estado. Legalidad e ilegalidad se convierten en dos caras del mismo proyecto hegemónico, en el sentido de que la ley se cumple o no según el beneficio directo de los grupos dominantes.

La capacidad de la élite hegemónica no se reduce solo a hacer cumplir o no la ley. Es importante considerar que en los Estados modernos el sistema legal es una de las formas 
principales para institucionalizar las ideas hegemónicas existentes. Así, la ley "manifiesta poder de varios tipos, incluyendo la autoridad para legitimar ciertas visiones del orden social, determinar las relaciones entre las personas y los grupos, y manipular el entendimiento cultural y el discurso" (Lazarus-Black y Hirsch, 1994, p. 1).

De esta manera, la ley es un dispositivo de la hegemonía, no solo por su capacidad coercitiva, sino porque define lo que está bien y lo que está mal. La ley tiene un efecto performativo, y hasta pedagógico. Se convierte en un punto focal para la generación de un sentido común. Esto crea una relación estrecha entre ley y hegemonía. "Así como la ley reproduce una realidad social, la realidad social reproduce la ley. Cuando los individuos se definen como categorías legales particulares, estas categorías son reautorizadas y recreadas de forma continua" (Bibler-Coutin, 1994, p. 283).

Al dificultar la integración de los inmigrantes haitianos a la sociedad dominicana, la regulación migratoria no solo le desprotege sus derechos, sino que contribuye a generar un imaginario social sobre esta población en el que se les define como "parias" y cuya exclusión económica, política y social está justificada. Asimismo, la ley traspasa este estatus a los descendientes de inmigrantes haitianos, quienes siguen siendo considerados "extranjeros" aunque hayan nacido en el territorio dominicano.

El resultado de la política migratoria dominicana, y en especial del marco jurídico que la regula, es palpable en la opinión pública dominicana. En efecto, según el estudio de cultura política del Barómetro de las Américas, en 2014 se registró un aumento en las actitudes racistas frente a los inmigrantes haitianos respecto de años anteriores (Espinal, Morgan y Zeichmaster, 2015).

Ahora bien, las instituciones formales funcionan en tándem con las informales. Al hablar de un orden hegemónico se toma en cuenta las leyes y las relaciones económicas, políticas, etc., que configuran la realidad social en la que tales leyes se aplican. En este sentido, la política migratoria del Estado dominicano responde a un orden autoritario y extractivista. De un lado, las leyes restrictivas impiden que los inmigrantes haitianos y sus descendientes obtengan arraigo en la sociedad dominicana, manteniéndolos en un estatus precario, sometiéndolos a deportaciones sumarias y presentándolos como eternamente extranjeros. Por el otro lado, el mismo Estado y sus agentes generan una apertura excepcional e informal que promueve la inmigración irregular. Así, cuando resulta económica o políticamente ventajoso, se les puede expulsar legalmente. De ahí que reclamar la protección de los derechos de los inmigrantes haitianos o los dominicanos de ascendencia haitiana, haciendo referencia a la institucionalidad democrática, ignora que dicha institucionalidad opera a través de dispositivos racistas, autoritarios y extractivistas. Por tanto, para lograr avances, se debe partir desde la conformación de espacios contrahegemónicos que reten el orden político existente. 


\section{Ciudadanía, derechos y contrahegemonía}

Es importante establecer que como estrategia hegemónica, la política migratoria dominicana es parte de un entramado político más amplio que afecta la forma en cómo las organizaciones de la sociedad civil, los partidos políticos y la ciudadanía en general plantean sus demandas democráticas. En este sentido, esta última sección analiza en primer lugar, cómo opera este marco más general sobre la lucha por los derechos de los inmigrantes haitianos y sus descendientes en la República Dominicana; y en segundo lugar, cuál estrategia es viable para superar los límites del institucionalismo que subyace en la forma de lucha por los derechos humanos en el país.

El discurso político dominante en la República Dominicana reduce la democracia a un mercado electoral en el que los ciudadanos expresan sus preferencias políticas a partir del criterio de una buena gestión pública (Morel, Melgen y Muñiz, 2016). A las organizaciones de la sociedad civil se las circunscribe al rol de portavoces de las demandas de la ciudadanía dentro de las instituciones existentes, con el objetivo de disciplinar a los ciudadanos en la forma correcta de reclamar sus derechos (Morel, Melgen y Muñiz, 2016). Al mismo tiempo se promueve una visión sumisa de la ciudadanía, al señalar que la democracia implica siempre la obediencia a la autoridad establecida (Muñiz, Melgen, Morel y Balbuena, 2017).

Junto a lo anterior se abre una dicotomía entre lo social y lo político. En ese discurso dominante, las demandas democráticas (como mejor calidad de vida para los inmigrantes y sus descendientes) son parte de lo social, pero no de lo político. Esto último es presentado como la administración técnica de la cosa pública, que incluye el manejo y procesamiento de esas demandas (Morel, Melgen y Muñiz, 2016). Dentro de este marco, la lucha por los derechos de los inmigrantes haitianos y sus descendientes se plantea desde la sumisión y la súplica. Es decir, no se plantea con el objetivo de ocupar espacios de poder en el Estado, sino de buscar aliados en el Estado, sin considerar el rol que estos juegan en el orden hegemónico actual.

Esta dicotomía entre lo social y lo político funciona como un dispositivo del discurso hegemónico para evitar que las demandas democráticas de la ciudadanía y las luchas de poblaciones vulnerabilizadas pongan en cuestión el poder político (Morel, Melgen y Muñiz, 2016). Las organizaciones de la sociedad civil que defienden los derechos humanos no tienden a cuestionar el poder político, puesto que su labor consiste en trabajar casi exclusivamente dentro del orden institucional existente; en consecuencia no ponen en juego el poder político.

Lo que esconde esta narrativa es que las decisiones políticas quedan bajo el control de quienes ocupan y dirigen el Estado, y dado que la lucha por los derechos es desvinculada de la lucha por el poder, queda reducida a un simple simulacro (incapaz de cambiar la realidad). Un ejemplo de esto es la propia lucha contra la Sentencia 168/13 que desembocó 
en la referida Ley 169-14, como se argumentó en el apartado II, la ley significó la continuidad del proceso de exclusión a través de un desorden legal organizado. ${ }^{3}$

Lo anterior ocurre por la ausencia de un campo contrahegemónico en la política dominicana (Morel, Melgen y Muñiz, 2016). Esto se evidencia en la ausencia de un abordaje al tema de la migración por parte de los principales partidos políticos dominicanos, más allá de comprometerse a cumplir la ley. Estos partidos políticos dominicanos operan desde un marco nacionalista que promueve actitudes intolerantes contra los inmigrantes haitianos. Esto genera que en la población dominicana, quienes militan en partidos políticos tienden a expresar actitudes menos tolerantes hacia estos inmigrantes que las personas que no militan en ningún partido (Muñiz, Melgen, Morel y Balbuena, 2017). Ahora bien, tampoco las organizaciones de la sociedad civil han planteado su lucha en términos políticamente relevantes, que obliguen a los partidos a posicionarse en uno $u$ otro sentido.

Esto es lo que implica la lucha política: redefinir la hegemonía. Como explica Joseph (2002), la hegemonía no es solo creada por grupos sociales, sino que es reactualizada por las acciones de estos. Es decir, que si bien los actores siempre actúan dentro de un marco hegemónico, estos tienen la posibilidad actuar estratégicamente para conservar o transformar dicho marco. Por consiguiente, se trata de definir una estrategia contrahegemónica que haga frente a la exclusión. Justamente esta es la historia que envuelve el concepto de ciudadanía.

La ciudadanía es "la relación entre práctica política que crea comunidad política, y las comunidades políticas que dan espacio a la praxis política" (Spanakos, 1999, p. 267). Es decir, la ciudadanía no es solo un atributo, sino una aspiración. Al mismo tiempo, el concepto de ciudadanía implica un modelo de organizar lo político según el cual los integrantes de una comunidad política reconocen mutuamente una "magistratura indeterminada" que faculta a quienes la ejercen a participar de las decisiones de la comunidad política formada por los conciudadanos (Balibar, 2013).

Por esta razón, la ciudadanía es inherentemente un aspecto contencioso dentro de cualquier comunidad. Es decir, la ciudadanía no está predefinida, sino que ella se constituye constantemente a través de la lucha política. La constitución de la ciudadanía es en sí misma una lucha por establecer criterios de inclusión y exclusión, es decir, por determinar quiénes forman parte de la comunidad política y quiénes son extraños en esta (Balibar, 2013). En consecuencia, definir la ciudadanía implica siempre una lucha por la hegemonía.

3 Otros ejemplos en la República Dominicana son la lucha por el derecho al aborto (la República Dominicana es uno de los pocos países del mundo que lo criminaliza en todos los casos), que sigue el mismo patrón institucionalista que la convierte en una lucha sin contenido político (Balbuena, 2018), o la lucha por el fin de la impunidad, que si bien generó movilizaciones masivas en el país durante el año 2017, nunca pudo retar el poder político (Dotel, 2017). 
Lo anterior también nos permite entender que los procesos de exclusión social no resultan en la anulación completa de la agencia de los grupos excluidos (Spanakos, 1999), y que por su posición dentro de la economía dominicana los inmigrantes haitianos y sus descendientes tienen la capacidad de ejercer presión política en el país. Así, resulta patente cómo puede configurarse su lucha por cuestionar la hegemonía política al resignificar la ciudadanía y la política de la República Dominicana.

Esta lucha solo puede plantearse desde la política, y con el objetivo de enfrentar y cambiar el poder político establecido. Para superar los límites que enfrentan las organizaciones de la sociedad civil dominicana que representan comunidades vulnerabilizadas, como los inmigrantes haitianos y los dominicanos de ascendencia haitiana, su lucha se debe asumir desde el "derecho a tener derechos", que es la base de la constitución de una ciudadanía democrática. Este reclamo opera como interpelación a los demás segmentos de la ciudadanía, con un contenido universalizable enmarcado en un discurso de inclusión generalizado, y por lo tanto democrático.

El reto para los actores políticos democráticos en la República Dominicana es integrar sus demandas concretas en el marco de un relato político contrahegemónico. Esto no es posible si dicho relato no parte de un análisis político sobre cuál capacidad de acción asiste a la ciudadanía como sujeto de la democracia, y cómo esta se articula políticamente para enfrentar a los grupos privilegiados que deniegan sus derechos.

\section{Conclusión}

En este artículo se ha argumentado que las políticas migratorias del Estado dominicano se enmarcan en una estrategia de doble cara. Por un lado, el empleo de trabajadores migrantes haitianos busca mantener una oferta de fuerza de trabajo barata, necesaria para ciertas industrias con bajo desarrollo tecnológico y poca competitividad; por el otro lado, el establecimiento de medidas cada vez más restrictivas provoca que los inmigrantes haitianos y los dominicanos de ascendencia haitiana se vean excluidos de los espacios formales de la política y se encuentren en un estado de desarraigo.

Asimismo, se ha explorado cómo la lucha por la realización de sus derechos humanos puede servir como punto de anclaje para las luchas políticas de los inmigrantes haitianos y los dominicanos de ascendencia haitiana. En otras palabras, luchar desde la arena política por los derechos humanos es una praxis que crea ciudadanía y profundiza la democracia, independientemente del reconocimiento formal del Estado. Lo importante es reconocer que la ciudadanía es más que un estatuto legal, es un vínculo político que nace de la praxis de esas luchas. 
En la medida en que la política migratoria del Estado dominicano se ha concentrado en crear espacios de exclusión legal, la forma de subvertirlos es plantear la lucha por los derechos de inmigrantes haitianos y dominicanos de ascendencia haitiana como un aspecto central de la política dominicana contemporánea. Tomarse en serio los derechos humanos implica la oportunidad para una acción de política radical, dirigida a redefinir el concepto de ciudadanía y a cuestionar las políticas excluyentes del Estado dominicano. En efecto, al concebir la ciudadanía en términos de agencia para la construcción de una democracia plural sustentada en la realización de los derechos humanos, se abre un horizonte de acciones dirigidas a disputar el poder. La ciudadanía deja de ser exclusivamente un concepto legal, y pasa a pertenecer a quien actúa por la realización de sus derechos y, en consecuencia, disputa la hegemonía, tomando como referencia una comunidad política concreta sin importar que otros integrantes de esa comunidad pretendan su exclusión.

\section{Referencias}

Antonin, A. (1982). Haití en el Caribe. Nueva Sociedad, 63, 103-112. Recuperado de https://nuso.org/media/articles/downloads/1003_1.pdf

Augelli, J. P. (1980). Nationalization of Dominican borderlands. Geographical Review, 70(1), 19-35. Recuperado de https://doi.org/10.2307/214365.

Balaguer, J. (1989). La isla al revés: Haití y el destino dominicano. Santo Domingo, República Dominicana: Fundación José Antonio Caro.

Balbuena, A. (2018). El debate sobre el aborto y las tres causales: La cuestión de la autonomía de la mujer. Perspectivas, (2-18), abril. Recuperado de https://docs.wixstatic.com/ugd/19a8bc_c1c7140bb47a43bdbabbbafd1993e6a2.pdf

Balibar, E. (2013). Ciudadanía. Buenos Aires, Argentina: Adriana Hidalgo Editora.

Belique, A. M. (2017). Apátridas, segregación racial y violación de derechos: balance y retos tras cuatro años de la sentencia. Perspectivas, (6-17), diciembre. Recuperado de: http://library.fes.de/pdf-files/bueros/fescaribe/14840.pdf

Bibler-Coutin, S. (1994). Enacting law through social practice: sanctuary as a form of resistance. En M. Lazarus-Black y S. F. Hirsch (Eds.), Contested states: law, hegemony, and resistance (pp. 282-304). Nueva York: Routledge.

Bosch, M., Pérez, M. y Rodríguez, J. (2018). El acceso de inmigrantes y descendientes a la salud y la protección social en la República Dominicana. Estudio complementario de la segunda encuesta nacional de inmigrantes 2017. Santo Domingo: Fondo de Población de las Naciones Unidas. Recuperado de https://dominicanrepublic.unfpa.org/es/publications/el-acceso-de-inmigrantes-ydescendientes-la-salud-y-la-protección-social-en-la 
Cáceres, F.I., Lozano, W., Durán, R., Montero, J. y Otáñez, W. (2018) Segunda encuesta nacional de inmigrantes de la República Dominicana ENI-2017: Informe general. Santo Domingo: Fondo de Población de las Naciones Unidas. Recuperado de https://dominicanrepublic.unfpa.org/es/publications/informe-general-de-la-segundaencuesta-nacional-de-inmigrantes-eni-2017

Capdevila, L. (2004). Una discriminación organizada: las leyes de inmigración dominicana y la cuestión haitiana en el siglo XX. Tebeto: Anuario del Archivo Histórico Insular de Fuerteventura, 5, 438-454. Recuperado de https://dialnet.unirioja.es/servlet/articulo?codigo $=5889867$

Castillo, J. M. (2012). La nacionalidad dominicana. Santo Domingo: Editora Nacional.

Centro Bonó (2015). Balance General Ley 169-14 promulgada 23 de mayo 2014, a 1 año de estar en vigor. Santo Domingo: Centro Bonó. Recuperado de https://reconoci.do/wp-content/uploads/2014/12/Balance-Ley-169-14-ColeccDDHH-Centro-Bon\%C3\%B3.pdf

Ciriaco, A. y Vargas, L. H. (2018). Aporte al valor agregado de la población de origen extranjero en la República Dominicana. Estudio complementario de la segunda encuesta nacional de inmigrantes 2017. Santo Domingo: Fondo de Población de las Naciones Unidas. Recuperado de https://dominicanrepublic.unfpa.org/es/publications/aporte-al-valor-agregado-de-lapoblación-de-origen-extranjero-en-la-república

Consultoría Ejecutiva del Poder Ejecutivo (2015). Constitución de la República Dominicana 2015. Gaceta Oficial $\mathrm{N}^{\circ}$ 10805, 13 de junio. Recuperado de: http://www.consultoria.gov.do/

Corte IDH. Caso de Personas dominicanas y haitianas expulsadas vs. República Dominicana, (Excepciones Preliminares, Fondo, Reparaciones y Costas), Sentencia de 28 de agosto de 2014, Serie C No. 282.

Corte IDH. Caso Nadege Dorzema y otros vs. República Dominicana, (Fondo, Reparaciones y Costas), Sentencia de 24 de octubre de 2012, Serie C No. 251.

Corte IDH. Caso de las niñas Yean y Bosico vs. República Dominicana, (Excepciones Preliminares, Fondo, Reparaciones y Costas), Sentencia de 8 de septiembre de 2005. Serie C No. 130.

Del Castillo, J. (2005). La formación de la industria azucarera dominicana, 1872-1930. Clío, 169, 11-76. Recuperado de http://www.academiadominicanahistoria.org.do/ index.php/revista-clio/

Dilla, H. (2004a). Intercambio desigual y complejos urbanos binacionales en la frontera dominicana con Haití. Estudios Fronterizos, 5(9), 35-58. Recuperado de: http://www.scielo.org.mx/scielo.php?script=sci_arttext\&pid=S018769612004000100002

Dilla, H. (2004b). República Dominicana y Haití. Entre el peligro supuesto y el beneficio tangible. Nueva Sociedad, 192, julio-agosto, 23-33. Recuperado de: 
https://nuso.org/articulo/republica-dominicana-y-haiti-entre-el-peligro-supuesto-yel-beneficio-tangible/

Dirección General de Migración. (2017). Conozca los requisitos del Plan Nacional de Regularización. (En línea). Recuperado de: https://www.migracion.gob.do/prccm/

Dotel, O. (2017). Fin de la impunidad: entre lo social y lo político. Reflexiones sobre la Marcha Verde y el rol de los partidos de oposición. Perspectivas, (2), agosto. Recuperado de: http://library.fes.de/pdf-files/bueros/fescaribe/14838.pdf

Eller, A. (2016). We dream together: dominican independence, Haiti, and the fight for caribbean freedom. Durham, EE. UU.: Duke University Press.

Espinal, R., Morgan, J. y Zechmeister, E. (2015). Cultura política de democracia en República Dominicana y en las Américas: gobernabilidad democrática a través de 10 años del Barómetro de las Américas. Santo Domingo: USAID-Universidad Vanderbilt. Recuperado de:

http://www.vanderbilt.edu/lapop/dr/AB2014_Dominican_Republic_Country_Repor t_V6_W_081815.pdf

Espinal, R. (2018). Descendientes de inmigrantes en la República Dominicana. Estudio complementario de la segunda encuesta nacional de inmigrantes 2017. Santo Domingo: Fondo de Población de las Naciones Unidas. Recuperado de: https://dominicanrepublic.unfpa.org/es/publications/descendientes-de-inmigrantesen-la-república-dominicana

Ferguson, J. (2003). Migration in the Caribbean: Haiti, the Dominican Republic and beyond. Londres: Minority Rights Group International. Recuperado de:

https://minorityrights.org/publications/migration-in-the-caribbean-haiti-thedominican-republic-and-beyond/

Fletcher, L., y Miller, T. (2004). New perspectives on old patterns: forced migration of haitians in the Dominican Republic. Journal of Ethnic and Migration Studies, 30(4), 659-679. Recuperado de:

https://www.tandfonline.com/doi/abs/10.1080/13691830410001699504

García-Peña, L. (2016). The borders of dominicanidad: race, nation, and archives of contradiction. Londres: Duke University Press.

Gramsci, A. (2011). Prison Notebooks. Nueva York: Columbia University Press.

Howard, D. J. (2001). Coloring the Nation: Race and Ethnicity in the Dominican Republic. Oxford, UK-Boulder, EE. UU.: Signal Books, L. Rienner Publishers.

Joseph, J. (2002). Hegemony: A realist analysis. Londres: Routledge. Recuperado de http://search.ebscohost.com/login.aspx?direct=true \&scope=site $\& d b=$ nlebk $\& d b=$ nla bk\&AN=92421

Kristensen, K. y Wooding, B. (2013). Haiti/Dominican Republic: upholding the rights of immigrants and their descendants. NOREF Reporte, octubre. Recuperado de: https://www.files.ethz.ch/isn/172091/273b4770daf48a18c60d724a641f0470.pdf 
Laclau, E. (2000). Identity and hegemony: the role of universality in the constitution of political logics. En J. Butler, E. Laclau y S. Zizek (Eds.), Contingency, hegemony, universality: contemporary dialogues on the left (pp. 44-89). Londres: Verso.

Lazarus-Black, M. y Hirsch, S. F. (1994). Performance and paradox: exploring law's role in hegemony and resistance. En M. Lazarus-Black y S. F. Hirsch (Eds.), Contested states: law, hegemony, and resistance (pp. 1-30). Nueva York: Routledge.

Ley de Inmigración No. 95. Gaceta Oficial No. 5299, Ciudad Trujillo, República Dominicana, 17 de abril de 1939. Recuperada de: http://www.acnur.org/biblioteca/pdf/0239.pdf?view=1

Ley General de Migración No. 285-04. Gaceta Oficial No. 10291, Santo Domingo, República Dominicana, 15 de agosto de 2004. Recuperada de: http://www.consultoria.gov.do/

Ley No. 169-14, que establece un régimen especial para personas nacidas en el territorio nacional inscritas irregularmente en el registro civil dominicano y sobre naturalización. Gaceta Oficial No. 10756, Santo Domingo, República Dominicana, 26 de mayo de 2014. Recuperada de: http://www.consultoria.gov.do/

Ley No. 199, que aprueba el Modus Operandi con la República de Haití. Gaceta Oficial No. 51395, Ciudad Trujillo, República Dominicana, 20 de diciembre de 1939. Recuperada de: http://www.consultoria.gov.do/

Lizardo, J. y Grateraux, C. (2013). El aporte de los trabajadores inmigrantes a la actividad económica en la República Dominicana: Una primera aproximación. Estudio complementario a partir de la ENI 2012. Santo Domingo: Fondo de Población de las Naciones Unidas. Recuperado de:

https://dominicanrepublic.unfpa.org/es/publicaciones/el-aporte-de-los-trabajadoresinmigrantes-la-actividad-económica-en-la-república

Lozano, W. (1998). Jornaleros e inmigrantes. Santo Domingo: Instituto Tecnológico de Santo Domingo.

Lozano, W. (2011). Geopolítica de la reconstrucción de Haití y la cooperación insular en la Hispaniola. Ciencia y Sociedad, 36(4), 561-589. Recuperado de: https://www.redalyc.org/pdf/870/87022786001.pdf

Martínez, S. (1999). From hidden hand to heavy hand: sugar, the state, and migrant labor in Haiti and the Dominican Republic. Latin American Studies Association, 34(1), 5784. Recuperado de: https://www.jstor.org/stable/2503926?seq=1\#page_scan_tab_contents

Martínez, S. (2003). Not a cockfight: rethinking haitian-dominican relations. Latin American Perspectives, 30(3), 80-101. Recuperado de: https://www.jstor.org/stable/3185037?seq=1\#page_scan_tab_contents

Martínez, S. (2014). The price of confrontation: international retributive justice and the struggle for haitian-dominican rights. En G. Andreopoulos y Z. F. Kabasakal (Eds.), 
The uses and misuses of human rights (pp. 89-116). Nueva York: Palgrave Macmillan

Mayes, A. J. (2015). The mulatto republic: class, race, and dominican national identity. Gainsville, EE. UU: University Press of Florida.

Mateo, A. (2004). Mito y cultura en la era de Trujillo. Santo Domingo: Editora Manatí.

Ministerio de Trabajo-Observatorio del Mercado Laboral Dominicano (ONLAD). (2011). Inmigrantes haitianos y mercado laboral: estudio sobre los trabajadores de la construcción y de la producción del guineo en la República Dominicana. Santo Domingo: Autores. Recuperado de:

http://mt.gob.do/transparencia/index.php/publicaciones/category/publicaciones2010

Morel, C., Melgen, L. y Muñiz, A. (2016). Narrativas sobre la democracia dominicana del siglo 21. Santiago, República Dominicana: Instituto ISD. Recuperado de: https://www.institutoisd.org/publicaciones

Muñiz, A., Melgen, L., Morel, C. y Balbuena, A. (2017). Imaginar el futuro: ciudadanía y democracia en la cultura política dominicana. Santiago, República Dominicana: Instituto ISD. Recuperado de: https://www.institutoisd.org/publicaciones

Petroziello, A. (2012). Haitian construction workers in the Dominican Republic: An exploratory study on indicators of forced labor. Washington, D.C.: Departamento de Trabajo de los Estados Unidos. Recuperado de:

https://digitalcommons.ilr.cornell.edu/cgi/viewcontent.cgi?article=2813\&context=k ey_workplace

Resolución No. 3200, Resolución del Congreso Nacional que aprueba el Acuerdo Suscrito entre la República Dominicana y la República de Haití, sobre Jornaleros Temporeros Haitianos. Gaceta Oficial No. 7391 del 23 de febrero de 1952, Ciudad Trujillo, República Dominicana. Recuperada de: http://www.consultoria.gov.do/

Ricourt, M. (2016). The dominican racial imaginary: surveying the landscape of race and nation in Hispaniola. Critical caribbean studies. New Brunswick, EE. UU.: Rutgers University Press.

Spanakos, A. (1999). Democracia, ciudadanía e identidad en la República Dominicana: con cuál demos y cuál kratos. En R. Brea, R. Espinal y F. Valerio-Holguín (Eds.), La República Dominicana en el umbral del siglo XXI: cultura, política y cambio social (pp. 259-279). Santo Domingo: Pontificia Universidad Católica Madre y Maestra.

Théodat, J. M. (1998). Haïti-Quisqueya: une double insularité. Mappemonde, 51(3), 7-11. Recuperado de https://www.mgm.fr/PUB/Mappemonde/M398/Theodat.pdf

Thomas, P. (2010). The Gramscian moment: philosophy, hegemony and Marxism. Chicago: Haymarket. 